\title{
Healthful Eating, the Western Style Diet and Chronic Disease
}

\author{
James Varani* \\ Department of Pathology, USA \\ *Corresponding author: James Varani, Department of Pathology, Ann Arbor, MI 48109, USA \\ Submission: 啙 September 26, 2017; Published: 些 November 03, 2017
}

\section{Opinion}

The term "Western-style diet" refers to an eating pattern that includes a high content of saturated fat, a large amount of processed carbohydrate and too many calories. In common usage, the term Western style diet is pejorative; it connotes a pattern of eating which is essentially unhealthy. Consumption of the Western style diet is strongly linked with the growing epidemic of obesity in the United States and throughout the Western World [1,2]. It is associated with numerous chronic age-related ailments. Among these are cancer (especially colon and breast), cardiovascular diseases and metabolic diseases (metabolic syndrome, type II diabetes and in the liver, specifically, non-alcoholic fatty liver disease (NAFLD). Associations with osteoporosis, chronic kidney disease, earlyonset dementia and skin diseases have also been suggested [3-10]. Once largely confined to societies in North America, Europe and Australia, the Western style diet is now a world-wide phenomenon.

The purpose of this opinion piece is not to argue against the Western style diet (or for it, for that matter). Rather, the purpose is simply to point out (the obvious) that the term Western style diet does not refer to a single eating pattern. For many individuals, a Western style of eating includes red meat, dairy products and poultry. For others, highly processed oils, refined sugar and highfructose corn syrup are dietary mainstays. These are very different diets. For some individuals, meat, dairy products and poultry are consumed fresh; for others, the raw food materials have been extensively processed prior to consumption. In some cases, preservation processes have maintained much of the original food value, but in others cases, the processing has been less efficient at doing this. For some individuals, meat, dairy products and poultry are consumed with large amounts of whole grains, vegetables and fresh fruits. For others, fresh fruits and vegetables are not, typically, part of the diet. Where in lie the problem(s)? In the view of this author, the problem does not lie, primarily, in the consumption of fresh meat, dairy products and poultry. The problem, rather, is reliance on extensively processed food products-especially oils used in frying and sugars in used in beverages - as a major source of calories. And here, the problem is not only what is consumed, but what is missing.

We were all taught that healthful eating equates with ingesting an adequate supply of proteins, carbohydrates and essential fats.
Equally important are the vitamin and mineral cofactors, without which many of the necessary metabolic transformations of ingested proteins, carbohydrates and fats cannot occur. We know what most of the important vitamins and minerals are and the foods in which they are well-represented; recommended daily intake level for these are available. Beyond these are the minor trace elements and other cofactors. Some are needed in such small quantities that we do not even know they exist or have recommended in take levels. Still, they are necessary.

Our own research has focused on calcium and other trace elements. An insufficient supply of dietary calcium is an independent risk factor for virtually all of the same chronic ailments associated with excess consumption of saturated fat and, processed carbohydrate [11-13]. Sadly, many individuals in our society do not achieve even minimal intake levels of calcium. The USDA, in its most recent summary of critical nutrients, concluded that a high percentage of individuals in multiple age groups failed to reach minimal recommended calcium intake [14]. A similar situation exists in Europe and Australia $[15,16]$. The same conclusion can be reached for other trace elements that are nutritionally associated with calcium

This brings us to the major point of the opinion piece-i.e., the role of meat, dairy products and poultry in a healthy diet. To argue that consuming a wide variety of food stuffs provides a way to obtain all of the necessary dietary components is not, itself, a strong endorsement for a meat, dairy product and poultry-based diet. Vegetarians and vegans have proven that. Alternatively, the fact that vegetarians and vegans can thrive without consuming animalbased products is not a strong argument against a meat-based diet. One needs to directly determine the value of each food product or group of products as a contributor to a healthful diet. Where do we stand in regard to this? Leaving aside questions such as fresh versus processed, optimal quantities for maintaining health (including a healthy weight) and balance among individual food components etc., do we have sufficient knowledge to address the basic questioni.e., health-consequences (good or bad) of a diet based largely on consumption of meat, dairy products and poultry? In my view, while there are still huge gaps in our knowledge base, evidence that these products, especially dairy products, contribute to human health is compelling. Long-term epidemiological studies in humans 
support the relationship between consumption of dairy products and reduced incidence of several chronic diseases including colon cancer [17-21]. Experimental studies in animals are supportive [22]. Underlying mechanisms are not fully understood, but dairy products are rich in calcium and vitamin D. Epidemiological studies and interventional studies have shown similar trends between calcium / vitamin D intake and reduced chronic disease risk [11-13]. Calcium and vitamin D are critical to epithelial cell differentiation [23]. Differentiation, in turn, regulates growth (reducing outgrowth of premalignant lesions in organs such as the colon) and promotes barrier formation throughout the upper aerodigestive tract and digestive system (combating chronic inflammation).

The health benefits of calcium and vitamin D are undeniable. As a consequence, dietary supplements containing these agents have become plentiful. Unlike the situation with many other such supplements, the benefits of calcium- and vitamin D-containing supplements have been extensively studied. While there is evidence in favor of their use, the available data do not indicate that supplements with these agents can replace "healthful eating." With regard to the use of calcium supplementation for prevention of colon polyp formation, specifically, some recent interventional trials have found negligible benefit $[24,25]$. This is in contrast to earlier investigations that were more optimistic [26-28]. Likewise, studies focusing on calcium supplementation in osteoporosis have also reported beneficial changes in bone structure, but often only minimal change in osteoporotic bone fracture incidence [29]. What benefits there are must be balanced against other studies that have identified unwanted consequences, including increased risk of cardiovascular events with high calcium supplement use [30].

There are multiple reasons why substituting a dietary supplement for a variety of natural food products may not produce optimal results. For example, there is the issue of bioavailability. Effective utilization of any nutrient is influenced by other concomitantly present nutrients. When an essential vitamin or mineral is provided as part of a healthful diet, the milieu is different from when the same agent is taken as a supplement. Equally important, when a supplement providing only calcium (for example), is used, only calcium is ingested. Natural sources of calcium also contain additional trace elements and other bio-active components that are found in conjunction with calcium. Perhaps in most individuals, an adequate amount of any given minor nutrient will always be available. Yet, there will be the occasion individual who is deficient in one or more of these essential nutrients. For that person, a calcium supplement not containing the additional nutrient would be less beneficial than the natural calcium source.

In the final analysis, what constitutes a healthful diet has to be determined empirically. How meat, dairy products and poultry fit into a healthful eating regimen, likewise, needs to be based on appropriately conducted investigations. While this "opinion piece" supports the idea that a meat, dairy product and poultry-based diet Is (or can be) healthy, the gaps in our knowledge base are still large. If there is one "take home message" from this opinion piece, it is that more research is needed.

\section{References}

1. Ogden CL, Yanovski SZ, Carroll MD, Flegal KM (2007) The epidemiology of obesity. Gastroenterology 132(6): 2087-2012.

2. NCD Risk factor Collaboration (2016) Trends in adult body-mass index in 200 countries from 1975 to 2014: a pooled analysis of 1698 population-based measurement studies with 19.2 million participants. Lancet 387(10026): 1377-1396.

3. Heidemann C, Schulze MB, Frando OH, van Dam RM, Mantzoros CS, et al. (2008) Dietary patterns and risk of mortality from cardio vascular disease, cancer and all-causes in a prospective cohort of women. Circulation 118(3): 230-237.

4. Steyn NP, Mann J, Bennett PH, Temple N, Zimmet P, et al. (2004) Diet, nutrition and the prevention of type 2 diabetes. Public Health Nutr 7(1A): 147-165.

5. Odermatt A (2011) The Western-style diet: A major risk factor for impaired kidney function and chronic kidney disease. Am J Physiol Renal Physiol 301(5): F919-F931.

6. Cohen JC, Horton JD, Hobbs HH (2011) Human fatty liver disease: old questions and new insights. Science 332(6037): 1519-1523.

7. VernonG, Baranova A, Younossi Z (2011) Systematic review: the epidemiology and natural history of non-alcoholic fatty liver disease and non-alcoholic steatohepatitis in adults. Alimentary Pharmacol Thera 34(3): 274-285.

8. Prentice A (2004) Diet, Nutrition and the prevention of osteoporosis. Public Health Nutr 7(1A): 227-243.

9. Shakersain B, Santoni G, Larsson SC, Faxén-IG, Fastbom J, et al. (2016) Prudent diet may attenuate the adverse effects of Western diet on cognitive decline. Alzheimers Dement 12(2): 100-109.

10. Melnik BC (2013) Western-diet mediatedmTORC1-signaling in acne, psoriasis, a topic dermatitis, and related diseases of civilization Therapeutic role of plant-derived natural mTORC1 inhibitors. Chapter 37 In: Atson RRW \& Zibadi S (Eds.), Bioactive Dietary factors and Plant Extracts in Dermatology, Nutrition and Health; Springer Science+Business Media, New York, USA.

11. Peterlik M, Boonen S, Cross HS, Lamberg-AC (2009) Vitamin D and calcium insufficiency-related chronic diseases: an emerging world-wide public health problem. Int J Environ Res Public Health 6(10): 2585-2607.

12. Peterlik M, Cross HS (2009) Vitamin D and calcium insufficiency-related chronic diseases: molecular and cellular pathophysiology. Eur J Clin Nutr 63(12): 1377-1386.

13. Beto JA (2015) The role of calcium in human aging. Clin Nutr Res 4(1): 1-8.

14. US Department of Agriculture (2015) 2015-2020 Dietary Guidelines for Americans. ( $8^{\text {th }}$ edn), Washington DC, USA.

15. Medical Scientific Advisory committee (2015) Osteoporosis Australia Calcium factsheet

16. Scientific opinion on dietary references for calcium (2015) Euro Food Safety Authority 13: 4101.

17. Cho E, Smith-WSA, Spiegelman D, Beeson WL, van den Brandt PA, et al. (2004) Dairy foods, calcium, and colorectal cancer: a pooled analysis of 10 cohort studies. J Natl Cancer Inst 96(13): 1015-1022.

18. Flood A, Peters U, Chatterjee N, Lacey JV, Schairer C, et al. (2005) Calcium from diet and supplements is associated with reduced risk of colorectal cancer in a prospective cohort of women. Cancer Epidemiol Biomarkers Prev 14(1): 126-132.

19. Kesse E, Boutron-RMC, Norat T, Riboli E, Clavel-CF (2005) Dietary calcium, phosphorus, vitamin D, dairy products and the risk of colorectal adenoma and cancer among French women of the E3N-EPIC prospective study. Int J Cancer 117(1): 137-144. 
20.Larsson SC, Bergkvist L, Rutegard J, Giovannucci E, Wolk A (2006) Calcium and dairy food intakes are inversely associated with colorectal cancer risk in the Cohort of Swedish Men. Am J Clin Nutr 83(3): 667-673.

21.Park SY, Murphy SP, Wilkens LR, Nomura AM, Henderson BE, et al (2007) Calcium and vitamin D intake and risk of colorectal cancer: the Multiethnic Cohort Study. Am J Epidemiol 165(7): 784-793.

22. Beaty MM, Lee EY, Giauert HP (1993) Influence of dietary calcium on colon epithelial proliferation and 1,2-dimethyhydrazine-induced colonic cancer in rats fed high fat diets. J Nutr 123(1): 144-152.

23. Chakravarti B, Chattopadhyay N, Brown EM (2012) Signaling through the extracellular calcium-sensing receptor (CaSR). Calcium Signaling pp. 103-142.

24. Baron JA, Barry EL, Mott LA, Rees JR, Sandler RS (2015) A Trial of Calcium and Vitamin D for the Prevention of Colorectal Adenomas. N Engl J Med 373: 1519-1530.

25. Pommergaard HC, Burcharth J, Rosenberg J, Raskov H (2016) Aspirin, Calcitriol, and Calcium Do Not Prevent Adenoma Recurrence in a Randomized Controlled Trial. Gastroenterology 150(1): 114-122.
26. Baron JA, Beach M, Mandel JS, van Stolk RU, Haile RW, et al. (1999) Calcium supplements for the prevention of colorectal adenomas. Calcium Polyp Prevention Study Group. N Engl J Med 340(2): 101-107.

27. Wallace K, Baron JA, Cole BF, Sandler RS, Karagas MR, et al. (2004) Effect of calcium supplementation on the risk of large bowel polyps. J Natl Cancer Inst 96(12): 921-925.

28.Shaukat A, Scouras N, Schünemann HJ (2005) Role of supplemental calcium in the recurrence of colorectal adenomas: a metaanalysis of randomized controlled trials. Am J Gastroenterol 100(2): 390-394.

29. Clifford J, Rosen CJ, Anne KA (2009) Bone, Fat, and Body Composition: Evolving Concepts in the Pathogenesis of Osteoporosis. Amer J Med 122(5): 409-414.

30. Bolland MJ, Avenell A, Baron JA, Grey A, MacLennan G, et al. (2010) Effects of calcium supplements on risk of myocardial infarction and cardiovascular events. Brit Med J 341: c3691. 